\title{
EVENTS IN THE NETWORK SOCIETY: THE ROLE OF PULSAR AND ITERATIVE EVENTS
}

\author{
GREG RICHARDS \\ Academy for Leisure, NHTV Breda and Tilburg University, NHTV Breda, The Netherlands
}

\begin{abstract}
This conceptual article argues for a broader view of the role of events in social systems. When analyzed as social phenomena, events can be seen as social actors that have the potential to both sustain and transform social systems. The maintenance of social systems is often reliant on iterative events, regularly occurring celebrations that tend to confirm social structures. In contrast, pulsar events have the potential to transform social structures. In this sense events can be seen as actors that have important influences on social systems, particularly in linking localized small world networks with the global space of flows. These ideas are explored through the case of Barcelona, which illustrates the interplay between these different types of events in their total portfolio, and how the extension of ritual in the sense of Collins can also contribute to the generation of new relationships and practices in the contemporary network society. Barcelona is examined as an eventful city in which the alternation of continuity through iterative events and change through pulsar events contributes to increasing the network effects of events.
\end{abstract}

Key words: Event effects; Event portfolio; Social practices; Pulsar events; Iterative events; Barcelona

\section{Introduction}

Events have always had an important role in society-marking the significant moments that people share and that bind them together. In the past, most events were also an integral part of the social fabric, such as religious celebrations, cultural festivals, and the trading spaces provided by regular markets and fairs. The role of events as spaces of social interaction has in turn shaped the way in which people think about the spaces they inhabit:
Festivals influence people's idea of a city. They provide many points of identification and contribute to the birth of non-mainstream urban identities. They consolidate subcultures and create togetherness among amateurs of a common field. At their best festivals culminate in a "festival moment," creating a momentum born of dramaturgical excellence and high quality content, a powerful experience bringing together audience and festival performers and organisers. (Silvanto \& Hellman, 2005, p. 6)

Given the rapid pace of social, economic, and cultural change, events continue to take on new 
functions in society. Recent studies have observed the growth of events and festivals as economic catalysts (Getz, 2012), cocreation spaces (Crowther \& Orefice, 2015), as a stimulus for new governance models (Benneworth \& Dauncey, 2010), as innovation platforms (Hjalager, 2009), as media platforms (Rennen, 2007), and as hubs in global networks (Schüssler, Rüling, \& Wittneben, 2013). Much of this change can be linked to the development of what Castells $(1996,2009)$ has termed the "network society.” In an increasingly interconnected world, events also begin to take on new roles in connecting people, cultures, and ideas, and also connecting the local and the global. As such interconnections increase, there is also a growing interplay between the different events in the portfolio of places (Clark \& Misener, 2015; Ziakas \& Costa, 2011). There is increasing awareness that in addition to individual events having specific impacts, there are also synergies and network effects that can be developed between different events in the overall portfolio. For example, Ziakas (2014) proposes a holistic approach to the events portfolio in order to generate a stronger theoretical understanding of the relationship between places and events. Even so, as Clark and Misener (2015) note, understanding of these effects is sometimes lacking, and "there does not seem to be an overall strategy in terms of when and why to host small- versus large-scale events" (p. 18), or how the sequencing of events fits with overall urban strategies.

Relating event portfolios more closely to urban strategy requires us to think more deeply about the nature of events and the effects that events can have on each other as well as the places that host them. The argument presented here is that events not only have different impacts individually, but that events can also play a role as important social actors in shaping their own environment through systemic and structural effects.

\section{Events as Social Actors}

Recent shifts in social theory suggest that rather than simply being objects to be studied, events can also be seen as subjects, or actors in their own right that are capable of playing a role in social systems. If we look at actor-network theory (ANT), for example, objects (including events) and people are both seen as important actors in networks (Latour, 2005; van der Duim, 2007). Essentially, ANT recognizes that social phenomena such as events or tourist destinations are comprised of relationships that are both material (involving objects) and semiotic (conceptual) (Farías, 2012). The human actors responsible for making an event therefore use objects and interact with the semiotic meanings created by the event itself to form an apparently coherent whole. Thus, the idea of the Edinburgh Festival (not a single event, but a collection of many) encapsulates not just the people responsible for planning and executing the events in the city, but the physical locations used and the festivals themselves, which also begin to take on active roles in shaping the idea of the city. Events are therefore part of the physical and conceptual networks that underpin society. As such, Jarman, Theodoraki, Hall, and Ali-Knight (2014) argue that social-network analysis (SNA) is also a useful tool for analyzing events, because events can take an important role in embedding social networks and linking key actors together. SNA enables us to map the nodes supported by events, as well as the ties events can facilitate between social actors. Events are important to places because they help to coalesce the thick ties that underpin nodes in social networks as well as providing the links to other networks that can bring in resources and new ideas. Applications of SNA to specific events have been conducted in a small number of places (see Mackellar, 2006) and Stokes (2004) has developed a framework for analyzing the network relationships between events and tourism.

This network view of events as important actors in places suggests that we need to conceptualize events in new ways in order to account for their network effects, as well as their extensively researched place-specific effects in terms of economic, social, cultural, and environmental impacts and outcomes (e.g., Getz, 2012). Arguably, network effects, which include the development of collaboration, capacity building, and knowledge sharing, can have a much stronger effect on places in the long term than the impacts of individual events.

The events network of a place is not simply a collection of events of different types and sizes, but effectively can be seen as a small world network (Jarman et al., 2014) that can link actors together to 
create network effects, which in many cases are significant because of their ability to stimulate change in different sectors and in different locations. Jarman et al. (2014) illustrate how such effects operate in the case of Edinburgh, where small world networks operate at a large scale by linking smaller networks together, and can build trust and understanding between organizations and individuals, helping to retain knowledge and experience, facilitating shared identities and understandings, and supporting the development of local talent. The small world network that can emerge around events such as the Edinburgh Festival Fringe (Jarman et al., 2014) can arguably support the development of temporal clusters, which can be just as effective as catalysts for change as the development of permanent industrial or cultural clusters.

\section{From Event Portfolios to Event Networks}

Although events research has begun to consider more deeply the events portfolio of places (Ziakas \& Costa, 2011), the portfolio itself is usually analyzed in quantitative terms, with large scale, infrequently occurring mega-events at the top of the pyramid, and small scale, frequently staged community events at the base (Clark \& Misener, 2015; Getz \& Page, 2015). The potential qualitative differences between events as systemic actors embedded in networks are not foregrounded in this perspective. As Jarman (2013) also notes, "there is a paucity of research that describes and interprets their social networks" (p. 10). What is argued here is that events have qualitative as well as quantitative dimensions that need to be taken into account, particularly in terms of their ability to act in stimulating systemic change.

Much current event research is orientated towards single events, rather than evaluating the broader effects of the event portfolio as a whole. Within the portfolio, much research attention is also focused on mega-events, which Hall (2012) links to "grand statements of belief in the discourse of place competitiveness” (p. 128). Hall argues that this orientation tends to obscure the more cultural and social dimensions of smaller scale, regularly occurring events, and the focus on large scale event formulas also reduces the potential for event-based innovation. As Kavaratzis and Ashworth (2015) note, there is also often poor linkage between different events within the portfolio and between events and the city.

Arguably, the analysis of event portfolios needs to extend to interactions between different events in order to understand how they act to produce wider network effects and create small world networks. The aim of this article is to expand the view of events as social actors, arguing that events can act as catalysts for social change as well as underpinning existing social structures, depending on the nature of the event. In this sense it considers the differences between iterative and pulsar events as ideal types of events that can have differing effects on places. Drawing on social network analysis and ANT, this conceptual contribution reviews recent literature on the growing roles of events in the network society to show how iterative and pulsar events differ not just in terms of quantitative scale but also in terms of their qualitative effects on places. Starting with an analysis of the role of events in the contemporary network society, the article moves on to consider how theoretical perspectives on contemporary ritual and social networks can help us to identify the different effects of events. The consequences of iterative and pulsar events are then examined in more detail through a case study of events in Barcelona. It should be noted that the arguments developed here apply primarily to developed western societies, although the rapid globalization of event formats may also make them relevant in other areas as well.

\section{Events in the Network Society}

Castells (2009) argues that networks represent the new social morphology of contemporary society, such that the basic social structures and activities are organized around networks. He attributes the rise of the network society to three basic phenomena:

- A revolution in information technology

- Processes of globalization

- Emergence of a new form of organizationnetworking.

Due to the influences of globalization, the network society is organized around the opposition between the global and the local. Dominant processes in the 
economy are organized largely in global networks, which operate in what Castells (2009) calls the space of flows. The space of flows is contrasted to the sphere of day to day work, private life, and cultural identity-processes which are essentially local and territorial. Castells (2009) refers to this as the space of places. For Castells, in the space of places the local actors designated as programmers create and interpret content primarily within local networks, whereas switchers, who link different networks together, have a greater role in distributing, recirculating, and reinterpreting content between networks in the global space of flows.

From this viewpoint, events can play an important role in creating and circulating the cultural codes and content produced by local programmers in the network society, and therefore play an important role in the representation of places. They can support small world networks in those places by providing temporal focal points for the exchange of information and development of trust between actors (Jarman et al., 2014). Events can also serve to draw attention to places by marking them off temporally from other parts of the network, establishing them as the place to be during the event (Richards, 2013). Generating attention can also be an important part of establishing certain events as field-configuring events (Schüssler et al., 2013, p. 141) capable of shaping a particular sector or field of thought at a global level. An important underpinning of all of these network effects is the fact that physical events imply copresence between actors, even in an increasingly networked and virtual world (Richards, 2010).

In understanding the contemporary need for physical copresence (and therefore events) we can turn to the field of ritual, where we find ample basis for relating events to social systems and networks as important and necessary elements of social life: "Community events provide a space in which individuals with commonalities bind together in order to experience a sense of belonging” (Booth, 2014, p. 226). The work of Randall Collins (2004) provides an important starting point in the analysis of events in the network society. R. Collins has developed a theory of social interaction related to interaction ritual chains, which provides a mesolevel (community or locational level) theoretical link between a macrolevel (societal level) sociological theory of groups and microlevel (individual level) physiological theories. R. Collins' argument is that participation in rituals of all kinds is related to the production of emotional energy among participants. Emotional energy (or collective effervescence as originally formulated by Durkheim, 1915) is generated though physical copresence in situations in which there is a shared mood and focus of attention. People invest financial and time resources in rituals from which they expect to attain higher levels of emotional energy. If this expectation is met then people will seek out other rituals that can deliver this emotional high, leading to a chain of interaction rituals.

The important point raised by R. Collins' (2004) analysis is that rituals are capable of developing important social ties between those participating by ensuring physical copresence, generating mutual attention, and by structuring the field of action in both physical and temporal terms. Coming together physically in a ritual setting may provide a basis for bonding between groups of individuals, but the fact that people can move between rituals in search of new sources of emotional energy also implies the ability to forge new ties with other individuals and networks. So, rituals are important in building social capital, which Putnam (2000) sees as the collective value of all social networks. Within such networks both strong ties between actors in close and frequent contact with each other and weak ties with actors beyond the local events network are important (Granovetter, 1973). Strong ties help to create bonding and a feeling of belonging within the local network. This facilitates trust and makes transactions easier. The weak ties to those beyond the local network, however, provide new opportunities and a basis for innovation. Putnam (2000) also identifies two types of social capital: "bonding social capital" (related to strong ties) and "bridging social capital" (related to weak ties) (p. 23). Frequently-repeated events held in the same location may have the potential to increase bonding social capital and social cohesion, whereas new events may have potential for forging weak ties between social groups as individuals take up new rituals, giving the impetus for change and renewal. Events can both strengthen social structures through repetition and also change 
social structures by creating a gap between expectation and reality, as Sewell (1996) suggests. Similarly, Badiou (2005) in Being and Event opines that events happen in certain times and places which, unlike the minor contingencies of everyday life, rupture with the established order of things. The ability to both strengthen existing social structures and to challenge them through the introduction of new relationships and ideas is important in the network society, where established structures are challenged by the rapid reconfiguration of social relations under "liquid modernity,” as Bauman (2000) labels the increasingly transient nature of modern society.

It appears, therefore, that in the network society events have a potential double function: sustaining existing networks and network relationships through the development of strong ties and the generation of new relationships through weak ties. The actors identified as programmers by Castells (2009) might also be expected to play a more prominent role in supporting the development of strong ties in the small world networks of the space of places while the switchers can generate weak ties by linking networks together in the space of flows. One could therefore hypothesize a distinction between the strong ties generated by locally embedded events with a high degree of continuity and the weak ties created by more globalized events, which have greater potential to generate change. These two roles could be labeled as iterative events and pulsar events (the latter being a label more often applied in astrophysics, but also mentioned as a pulsar effect in the events field by Kammeier, 2002).

Iterative events generally have a maintenance function-bringing people together on a regular basis to cement strong social ties and generating bonding social capital. These events are usually more closely tied to the local, or what Castells (2009) calls the space of places. For the network, they are moments of togetherness. Pulsar events are potential moments of change that can lead to the development of new structures, links, and opportunities, generating bridging social capital. Pulsar events are more often linked to the global level, or what Castells refers to as the space of flows. Pulsar events may end up (even though we may not see it until after the event) being momentous.

Pulsar events thus belong to that "relatively rare subclass of happenings that significantly transform structure," and an eventful conception of temporality as "one that takes into account the transformation of structures by events” (Sewell, 1996, p. 262). Events have transformative effects in that "events transform structures largely by constituting and empowering new groups of actors or by re-empowering existing groups in new ways" (Sewell, 1996, p. 271). Some of the potential differences between iterative and pulsar events are outlined in Table 1 . This underlines that the differences between iterative and pulsar events can be drawn along many different dimensions, including social, cultural, economic, political, and temporal.

The temporal distinction between iterative and pulsar events may be of particular interest. As Moran (2013) notes, time is "an enacted, material, social practice that organizes the functions of temporality" (p. 7). Iterative and pulsar events may therefore be conceived of as two specific time practices. The first involves a cyclical series of events that is designed to support or strengthen the setting or structures that

Table 1

Characteristics of Pulsar and Iterative Events

\begin{tabular}{lll}
\hline & \multicolumn{1}{c}{ Iterative Events } & \multicolumn{1}{c}{ Pulsar Events } \\
\hline Main function & Maintenance of structures & Challenging and changing structures \\
Main actors & Programmers & Switchers \\
Nodal points & Small world networks, temporal clusters & Global fora \\
Change orientation & Conservatism, tradition & Dynamism, change \\
Temporal orientation & Event time & Linear or clock time \\
Social capital development & Bonding social capital & Bridging social capital \\
Human resource development & Developing local talent & Attracting external talent \\
Political/governance orientation & Building political support & Developing political agendas \\
Scope of attention & Local/national media & Global media \\
\hline
\end{tabular}


support it (as in the case of the Palio horse race in the center of Sienna, which has conserved the form of the space in which the race is staged through continual repetition, therefore also sustaining the ability of the city to stage the race in the urban center). A pulsar event, in contrast, is a practice designed to change structures - that is, it is an event in the sense meant by Sewell (1996) (i.e., as a gap between expectation and reality). For example, mega-events such as the Olympic Games are often used to change the image or physical layout of the host location. We should recognize, however, that the distinction between iterative and pulsar events is not always so clear. We may expect that a mega-event will be transformational, but the potential may not be realized, as in the case of the Athens Olympic Games in 2004 (Ziakas \& Boukas, 2014). Similarly, iterative events may end up changing structures over a long period of time, through small, iterative changes in the practice (Simons, 2014). This means it is important to study the effects of iterative and pulsar events, as well as their characteristics.

\section{The Effects of Pulsar and Iterative Events}

It is tempting to link small-scale community events to the realm of social maintenance and less regular mega-events to the role of rupture and innovation. However, the distinction between events is not necessarily one of size. The Olympic Games have just as much potential to become formulaic and to be tailored to regime maintenance as small community festivals. In this sense, many mega-events are now arguably part of a system of the serial reproduction of culture (Richards \& Wilson, 2006).

This is because events are not simply defined by their contents (meaningful experiences, in the definition of Getz, 2005, for example), but also by their consequences. The effects of events have usually been narrowly viewed in terms of their short-term impacts, but the really significant effects occur in the longer term, and involve systemic change. Change and novelty are built into the structure of events, which makes them an important social instrument:

events disappear as they emerge: they are no longer available to react in the following instant ... every event brings about a total change in past, present, and future-simply because it gives up the quality of being present to the next event and becomes a past for it (i.e., for its future). This minimal displacement can change the perspective of relevance that structures and bounds the horizon of past and future. In this sense, every event brings about a total modification of time. (Luhmann, 1995, p. 287)

According to Luhmann (1995), an event could be dramatic or eventful because it includes an information that can change "the state of the system and has thereby left behind a structural effect" (p. 67). But an event could also be a routine affair because "a piece of information that is repeated is no longer information. It retains its meaning in the repetition but loses its value as information" (Luhmann, 1995, p. 67). One of the qualities of an iterative event is the creation of a certain level of information redundancy through repetition, which makes it easier for insiders to absorb and internalize the cultural and social content of the event. This redundancy can create the barriers to outsiders that R. Collins (2004) considers an essential element of interaction rituals, which are often a feature of small world networks and many traditional events (Crespi-Vallbona \& Richards, 2007). Pulsar events, on the other hand, often have to rely on more formalized information content that makes the event easier to interpret for outsiders and which permits wider and more rapid circulation of event content and symbolism.

This indicates that iterative and pulsar events are not polar opposites: each event may contain the potential for continuity and change. As S. Collins (2012) notes, the opening and closing ceremonies of the Olympics have become a form of ritual that produces a standardized form, even in pulsar events. What is then interesting to consider is how events attain one function or the other, and how they may change their function at a certain moment in time. This is important for policy makers to consider, because their broad ranging event-related objectives often include both continuity and changerelated elements.

\section{Programming and Eventfulness: Strategies for Using Iterative and Pulsar Events}

Cities and regions are beginning to utilize the dialectic relationship between pulsar and iterative 
events in creative ways. Many cities already recognize the need to develop both large-scale events that will appeal to broad audiences and attract tourists and smaller, niche events that can build cohesion and identity. This is a basic principle in the programming strategy of Rotterdam Festivals (2015), for example, which mixes major summer festivals with smaller niche and lounge events in the city center. The festivals help to bring in large numbers of visitors and increase awareness of the city, while the niche events help to support specific groups and networking and socialization within the city.

This mix is important to the concept of eventfulness discussed by Richards and Palmer (2010) in their volume Eventful Cities. Through creative programming, cities and regions can develop both iterative events that generate bonding social capital and pulsar events that create bridging social capital. The mix of the two gives a change of pace and a diversity of experience that makes places attractive to residents and other stakeholder groups. Eventfulness therefore provides a mix of different types of events, of tempo, of scale, and intent. Eventful cities will consciously develop a range of different events that provide a range of desired outcomes as well as temporal and spatial variety in experience and meaning.

But eventfulness is not just a top-down, planned feature of place. Events are particularly important as traditional structures give way to more informal, bottom-up modes of association. The decline of social capital identified in the US by Putnam (2000) primarily signaled a drop in formal association, for example membership of clubs. However, this formal association is increasingly being replaced or augmented by informal modes (van Ingen \& Dekker, 2011) and by self-managing groups. These less formal links arguably rely even more heavily on events than traditional forms of association to promote physical interaction, because standard structures are often lacking. This is a development that Rojek (2014) notes in the creation of groups and (neo)tribes around relatively informal events, such as the Burning Man Festival.

A number of cities have now begun to utilize the dialectic relationship between pulsar and iterative events as a specific tool to develop eventfulness and to achieve wider policy goals. A recent longitudinal review of the cultural sector in Glasgow, for example, underlined how the city has managed to lever major events such as the Garden Festival (1988), European City of Culture (1990), Year of Visual Arts (1996), and UK City of Architecture and Design (1999), while at the same time supporting local vibrancy through small-scale events (Meyerscough, 2011). The city has achieved a similar feat in the field of sport, where encouragement of grass-roots sport played a role in the attraction and successful implementation of the 2014 Commonwealth Games (Commonwealth Games Federation, 2014).

In summary, events are temporal practices that can play an important role in social systems. Events may become both social actors and structures, organized both in a top-down and a bottom-up fashion. Both iterative and pulsar events have the potential to initiate significant network effects beyond the immediate context of the event itself. In social terms, they may help to strengthen existing structures, or give actors the power to challenge them. In temporal terms they may have roles in underpinning the linear time structures of modernity (Hughes, 1999) or they may be a device for reestablishing event time over linear or clock time by ignoring modern time structures (Simons, 2014). Spatially, they may also provide a link between the local place of spaces and the global space of flows, which in turn may generate opportunities for catalytic change.

These wider societal and network effects of events are illustrated in more detail in the case of the Catalan city of Barcelona.

\section{Pulsar and Interactive Events in Barcelona}

Barcelona has successfully used events to develop economic activity, attract tourism, and to raise its international profile (Smith, 2012). Richards and Palmer (2010) identify Barcelona as an eventful city, arguing that one of the keys to the successful development of events in Barcelona has been the creation of a balanced portfolio of major and communitybased events.

Richards (2007) describes how Barcelona used a succession of major events to position itself on the global stage, firstly through the World Exhibitions of 1888 and 1929 and then with the Olympic Games in 1992. Each of these events was used not 
just to attract media attention and tourism, but they also served to develop the structure of the city itself. The first World Exhibition was used to redevelop the Cuitadella area of the city, the second linked the Montjüic mountain to the city, and the Olympic Games continued to develop Montjüic, created the new Port Olympic area, and left a ribbon of facilities along the new orbital motorway around the city. Particularly the 1992 Olympics were credited with kick starting a renaissance of Barcelona, with a rapidly improving international image, strong tourism growth, inward investment, and infrastructure development (Duran, 2002).

The 1992 Olympics played an important role in creating a gap between expectation and reality, reimaging the Catalan port and industrial city as a cosmopolitan center of local and global culture (Dodd, 1999). They also served as an important political platform on which Catalan identity and aspirations to independence from Spain could be projected internationally (Hargreaves, 2000). In this sense, the Olympics were a recognizable historical event, in the terms of Sewell (1996). This event also had the effect of creating new expectations about the role of Barcelona as an eventful city (Richards \& Palmer, 2010).

The Olympics therefore served as an important bridge to the rest of the world that effectively bypassed the Spanish nation state. International media could be addressed directly, kick starting a wave of attention that has persisted up to the present day. The ability of Barcelona to position itself on the global stage was in large part due to key switchers, including Pasqual Maragall as Mayor of Barcelona and Joan Antoni Samaranch as a Catalan member of the International Olympic Committee (de Moragas \& Botella, 2002). But at the base of these international links was a series of small world networks rooted in the space of places of the city, supporting the development of the Olympic spirit, which in turn galvanized further change. In fact, the 1992 Olympics became the catalyst for further event creation in the city. From 2000 to 2004 a series of themed events were created, including the 2002 Gaudí year, which was widely hailed as a great success. The event boosted attendance at Gaudírelated attractions, with record numbers visiting his Sagrada Familia cathedral. The following Design Year in 2003 was also widely viewed as successful, although it operated on a different scale, appealing mainly to professional audiences of architects and designers. It can therefore be argued that the 1992 Olympics was a pulsar event that also had important local network effects.

The Universal Forum of Cultures staged in 2004 can, however, be viewed as an example of a failed pulsar event. This UNESCO-sponsored event was supposed to attract 7.5 million visitors and establish Barcelona as a global hub for intercultural dialogue. In fact, only about 2.9 million people attended the Forum, which instead became the stimulus for massive property development. Much derided by residents of Barcelona, it was effectively wiped from the city's memory, in an attempt to maintain the myth of Barcelona's event-based success (Richards \& Palmer, 2010). The Forum left a physical legacy in the shape of the Forum building, designed by Swiss architects Herzog and de Mueron, but the lack of legacy planning has left the Forum site largely unused for over a decade.

The failure of the Forum also signaled a potential end to the Barcelona model of urban development based on pulsar events (Smith, 2012). There was an inward turn by the city in terms of marketing and branding, and more concentration on iterative events and bonding social capital. Local programmers began to reclaim some of the ground they had lost during the post-Olympic rise of the global switcher. Encouragement from the public sector for grass-roots festivity also helped to link some more local events to international tourism flows (Richards, 2015).

After a post-Forum pause in the search for megaevents, the city once again began to set its sights on the Olympics - this time the Winter Games for 2026. Although the Games themselves are planned to be held in the Pyrenees, 2 hours away, Barcelona will act as the gateway for the Games. The snow-based events are planned to be held in the mountains, the ice-based events in Barcelona. A new ice-skating venue is planned for the city, but otherwise significant use will be made of the facilities developed for the 1992 Olympics, including the basketball facilities, the velodrome, and the Olympic Stadium. As the project website proclaims: "The project builds on the legacy of Barcelona '92 to give a new use to the great buildings that were designed decades ago and show that with minor interventions their current utility is unquestionable” (Barcelona Pireneus 
2026, 2014). In this way, the plans for a pulsar event in 2026 build on the pulsar event of 1992, just as the Olympic Games carried forward the urban development legacy of the World Expos held in the city in 1888 and 1929.

There is a clear recognition of the fact that pulsar events have helped propel Barcelona onto the global stage, and have been an important catalyst for change at key moments in the city's history.

If the '92 Games served to build the city at an urban level, giving it the necessary infrastructure and social organization, the 2026 Barcelona Pyrenees bid is a unique opportunity to better our city backbone with Catalonia, to consolidate its model of cohesive, open city with own personality, and to reassert its leadership. (Barcelona Pireneus 2026, 2014)

Such pulsar events have also been linked to specific governance regimes that help to create the support necessary for staging them. In Barcelona the postFranco emergence of a growth-orientated regime has stimulated the growth of pulsar events. These helped to link a wide range of stakeholders through publicprivate collaboration, providing a basis for architectural intervention and strategic planning based on good ideas rather than just big finance.

However, as the failure of the 2004 Forum shows, pulsar events have brought downturns as well as upturns in the economic, cultural, and social fortunes of the city. After the Olympics there was a post-mega-event let down, as the cultural sector suffered from a lack of investment after the largesse of the Games. Tourism also struggled as hoteliers tried to fill the new bed capacity built to accommodate the Olympic boom. In this event-created vacuum, however, opportunities also arose for new initiatives, such as the Sónar International Festival of Advanced Music and New Media Art. Founded in 1994, Sónar was essentially a grass-roots initiative, launched by a small group of electronic musicians. Only after the first couple of editions was it backed by the Municipality as a means of animating the new public spaces created for the Olympics in the old city.

One of the reasons for Sónar's success was the realization by the local programmers who organized it that the festival was becoming an important actor within the city. They tried to emphasize this by measuring the impact of the event in economic, social, and cultural terms, and in trying to build their networks with other key cities. By placing itself at the hub of a global music network this locally based initiative was successful in slowly developing itself into a pulsar event or switcher as it has grown internationally (Magaudda \& Colombo, 2010). Over the past 20 years, Sónar has become a global reference point in the electronic music scene, or what Schüssler et al. (2013) term a "field configuring event” (p. 141). In 2013 the event attracted 121,000 visitors, and the festival has now been globalized with editions taking place in different cities around the world. This indicates that an event that starts off as an iterative event can eventually develop into a pulsar event.

Similar embedding has happened in the field of sports events, with Barcelona becoming a major "sports city," with an estimated economic impact of $€ 2.1$ billion a year (Esports Barcelona, 2013). The small world network anchoring the sector includes the Olympic Studies Center, which collects and disseminates information on the effects of Olympic Games worldwide.

\section{Iterative Events in Barcelona}

As well as the high-profile major events, the large number of iterative, largely community-based events staged in the city make a huge contribution to eventfulness. Barcelona has over 6,000 popular fiestas and local events every year. Each neighborhood of the city has its own festa major or annual festival. Over 500 organizations are involved in producing these events, which together involve the active participation of 117,718 people and generate an estimated 28 million Euros in economic activity (Ajuntament de Barcelona, 2013).

The Festes de Gràcia is one such iterative grassroots event that has become increasingly significant for the residents of Barcelona, and now for tourists as well. Every August, a series of small streets in the neighborhood of Gràcia are decorated and become the stage for a 10-day celebration. Although this event is traditional, having been founded almost 200 years ago, like many other events in Catalunya it has been substantially reinvented to fit with the modern conception of Catalan identity and to meet the needs of a cosmopolitan city (Pablo, 1998). 
Although the tradition of street decoration has remained relatively unchanged, themes and spaces change frequently, creating a different event every year (Richards, 2015). One constant feature, however, is the emotional labor of the residents, who work year round to design and make the decorations. Most of these decorations are made of recycled materials, which involves the whole community in collecting and processing the material required. As Richards (2007) notes, this effort is sustained by an atmosphere of neighborly competition, with prizes being awarded for the best decorations. There is a direct relationship between hours invested and the number of prizes won by each street (Richards \& Palmer 2010). The prizes are not monetary, but rather expressed in terms of pride and joy in the recognition of the effort made.

The results of this effort now generate around two million visits a year, underlining the fact that an iterative event is not always small scale. But the management of the event remains local, being run by neighborhood associations with logistical support from the city in terms of security and marketing. At the level of iterative events, the Festes de Gràcia is an example of a community event that has become part of the local, national, and tourist agenda. This suggests a process of gradual emergence from below rather than imposition from above, but still with a relatively large scale. One interesting link between iterative events such as the Festes de Gràcia and pulsar events such as the 1992 Olympics is that the former have helped to sustain the cultural symbols that have subsequently been used to project Catalan identity at international level. The international circulation of such symbols and their use in the tourism industry has also helped to create more awareness among locally based iterative events of their own role as social actors in Barcelona. The identity of the local events sector has also been recognized by the Municipality, which recently produced a report on the Festive Movement of the city and its economic, cultural, and social value (Ajuntament de Barcelona, 2013).

In essence it seems that Barcelona has managed to combine pulsar and iterative events to generate both global (image change, tourism growth, urban redevelopment) and local (strengthening traditional culture and social cohesion) effects. These effects have not been achieved separately, or through portfolio synergies alone, but through linking pulsar and iterative events, programmers and switchers, and the local place of spaces with the global place of flows.

\section{Discussion: Dialectics of Pulsar and Iterative Events}

The grass-roots festivity developed by staging iterative events is arguably one of the factors that can ensure the success of pulsar events. The organizational capacity and social capital developed by local events provides the basis for staging events at a larger scale. In Barcelona, for example, the festive culture of the city, with its backbone of cultural associations, helped to support the vast volunteer effort necessary for the 1992 Olympics, estimated at $8 \%$ of the Catalan population (Pascual, Balta, \& Delgado, 2001). By linking the Olympics to local Catalan culture, Barcelona also ensured that the event gave a boost to grass roots events as well.

As the report on the Festive Movement in Barcelona (Ajuntament de Barcelona, 2013) notes, the link between iterative and pulsar events is nothing new:

In effect there is a tension between the defence of tradition and the "San Ferminisation" of some festivities, but the reality is that fiesta and folklore is a powerful tourist attraction. This link, however, is not new, people have always visited fiestas in other places. At the same time, the overexploitation and overcrowding can have a negative effect on the attraction that locals feel towards certain events.

The alternation of iterative and pulsar events seems to provide essential differences in scale and tempo that are arguably important to the creation of a feeling of eventfulness. Pulsar events provide a feeling of potential for change in the structures of everyday life. In the lulls between pulsar events, iterative events provide the regular social interaction essential to community maintenance and social cohesion. At the same time, the changes in structures initiated by pulsar events also help to shift the content and framing of iterative events, maintaining their relationship to contemporary needs.

At a local level, iterative events are usually grassroots initiatives. They need a certain level of political support, not just for legitimacy, but also to give access to public space. In general, however, they do 
not need to engage with the political agendas that are characteristic of governance regimes (Stone, 1993). This is evident in Barcelona in the case of the Feria de Abril, an event organized by Andalusian immigrants in the Catalan capital. Although the fiesta maintains a careful distance from the Catalan political agenda, it welcomes the support of local politicians who visit to generate mutual legitimacy (Richards, 2007). On the other hand, the Barcelona Olympics, as a major pulsar event, subsumed the independence agenda in many facets of its operation. This was essential to ensure the funding and political support needed to stage the event. Pulsar events are also much more reliant than iterative events on bridging social capital to link to different national and international networks. Iterative events focus much more on the bonding social capital that strengthens social cohesion in the location of the event itself. For the iterative event, therefore, one of the major challenges may be the stimulation of systemic innovation, whereas for the pulsar event the challenge is often local embedding.

These categories are not mutually exclusive, but rather can be seen as end members of a generalized continuum of event qualities and effects. Sometimes the roles of iterative and pulsar events may also be (temporarily) reversed, depending on their context. For example, iterative events that are basically conservative, and which underpin traditional structures, can become transformative when transplanted into a new context elsewhere. An interesting example is the North Sea Jazz Festival, which during its 30 year residence in The Hague in The Netherlands gradually grew to become a major international event and a mainstay of the cultural calendar of the Dutch capital. In 2006, the event was hijacked by neighboring Rotterdam, which could offer larger venues, more funding, and marketing muscle (van Aalst \& van Melik, 2012). In spite of complaints from regular visitors from The Hague, the move gave the event a new boost, and also had a significant effect on the jazz scene in the city. A new edition of the festival, North Sea Jazz Curaçao, also had a significant effect on this small Caribbean island:

The festival is ushering momentum through increased emotional bonding, stemming from higher levels of enjoyment and more socialization opportunities that benefit the overall Curaçao impression on the tourists who attend the festival. ... The festival's popularity is also manifested in the presence of new emerging segments. The Hispanic group is showing an increased interest in the festival and an opportunity exists to more effectively tap this newly emerged market segment. (Rivera \& Croes, 2012)

Analyzing how such events may have iterative or pulsar effects, and in particular how events may shift from being iterative to being pulsar, or vice versa, may be crucial in understanding the dynamics of event networks. There is a need to understand events as actors within the systems that create them (borrowing from ANT theory to analyze the combination of human actors and physical systems) and how these systems function to facilitate event creation and development (perhaps using SNA to uncover the small world networks that underpin events, and identifying the switchers capable of linking these networks to each other).

\section{Conclusions}

The analysis presented here suggests that a broadening of our view of events to include their role as actors within social systems and networks would be fruitful. There are indications that different types of events can have differing systemic effects, both in terms of the scope and form of change they can initiate. This is more than a question of event scale. It is also dependent on the differential temporal, social, cultural, and economic dimensions implied by pulsar and iterative events.

A number of observations flow from this analysis. Firstly, events have important network effects that can strengthen or challenge social structures. In general, iterative events tend to strengthen existing structures and network connections, providing moments when people can bond, whereas pulsar events have the potential to change the structures that have created them, and to become momentous in the process. Secondly, drawing on the work of Sewell (1996), we may only recognize the event itself as being momentous and transformational in hindsight, as the difference between expectation and reality becomes more observable. Thirdly, the potential for structural change also implies that events can be about more than their planned effects, because they also produce unplanned and unexpected 
effects. This is what makes events engaging for so many. This also implies that we need to look beyond the immediate content or experience of the event towards the longer term and wider effects, moving past the narrow event management paradigm criticized by Rojek (2013) and into a new networked view of events as social and cultural actors.

From a network perspective, events act not just as temporal nodes, but they can also help to shape the network itself in their role as global field-configuring events (Schüssler et al., 2013). But taking advantage of such systemic effects requires events to be embedded in place, so that they can link local small world networks with the global space of flows. The Barcelona case shows how collaboration between local programmers and global switchers can help to attract footloose mega-events and link these to local networks as well.

The contrast of different types and tempos of events also helps to produce a feeling of eventfulness (Richards \& Palmer, 2010) in places. Eventfulness can be produced because pulsar and iterative events work in different ways. Pulsar events can act as entrainment mechanisms for entire cities, regions, or countries. The Olympic Games and other pulsar events act as catalysts or coordination mechanisms to stimulate change within a spatially dispersed community, facilitating new connections. Iterative events such as the Festas de Gracia help to maintain the rhythm of place, and the entrainment process is based more on physical copresence and bonding processes. The combination of these different types of effects and temporal structures helps to underpin the eventfulness of places.

These qualities of events are arguably particularly valuable in the network society as described by Castells (2009). The ability of events to act as hubs, nodes, and temporal markers within networks means that they can provide a valuable structuring force in the face of the linear time tendencies of modernity (Hughes, 1999). Events become important social markers for both geographically proximate and dispersed global networks, underpinning regular sociality and stimulating new social contacts. From an events management perspective, one might also argue that such network effects may ultimately be more valuable than achieving a balanced portfolio of events for a specific place. Although a soundly structured events portfolio may help to create synergies between events within places, this approach may lead to opportunities for external networking and the creation of bridging social capital not being realized. One of the important dimensions of the sequencing of events within the portfolio (Clark \& Misener, 2015) could be the opportunities to collaborate with events and other actors external to the city, as the Sónar case study suggests. In essence, places need to think not just about events as recurring rituals, but as interaction ritual chains (R. Collins, 2004) in which continuity of event practices is combined with a search for new sources of emotional energy.

One of the main implications of this analysis is that there is a growing need to analyze the longerterm effects of events not just in terms of individual events, or even the events portfolio as a whole, but also in terms of the networks that shape and are shaped by those events. By identifying the small world networks that surround events, it should be possible to identify the programmers and switchers who are central to the creation, development, and eventual transformation of events. This might help to explain how and why some events are able to shift from being iterative events to pulsar events, and vice versa. This in turn may help us to understand the dynamics of individual events as well as the event portfolios of different places.

\section{References}

Ajuntament de Barcelona. (2013). Impacte del movement festiu a Barcelona. Retrieved from http://www.slide share.net/Barcelona_cat/impacte-del-moviment-festiuabarcelona

Badiou, A. (2005). Being and event. New York: Continuum.

Barcelona Pireneus 2026. (2014). Benefits. Retrieved December 16, 2014, from http://www.barcelonapirineus2026. org/en/benefits/

Bauman, Z. (2000). Liquid modernity. London: Polity.

Benneworth, P., \& Dauncey, H. (2010). International urban festivals as a catalyst for governance capacity building. Environment and Planning C: Government and Policy, 28(6), 1083-1100.

Booth, A. S. (2014). Performance networks: Indian cultural production in Aotearoa/New Zealand. Ph.D. thesis, University of Otago, Dunedin, New Zealand.

Castells, M. (1996). The Rise of the network society, the information age: Economy, society and culture (Vol. 1). Oxford: Blackwell.

Castells, M. (2009). Communication power. Oxford: Oxford University Press.

Clark, R., \& Misener, L. (2015). Understanding urban development through a sport events portfolio: A case study of 
London, Ontario. Journal of Sport Management, 29, 11-26.

Collins, R. (2004). Interaction ritual chains. Princeton, NJ: Princeton University Press.

Collins, S. (2012). Mediated modernities and mythologies in the opening ceremonies of 1964 Tokyo, 1988 Seoul and 2008 Beijing Olympic Games. The International Journal of the History of Sport, 29(16), 2244-2263.

Commonwealth Games Federation. (2014). XX Commonwealth Games post-Games report. Retrieved from http:// www.thecgf.com/games/2014/G2014-Official-PostGames-Report.pdf

Crespi-Vallbona, M., \& Richards, G. (2007). The meaning of cultural festivals: Stakeholder perspectives in Catalunya. International Journal of Cultural Policy, 13(1), 103-122.

Crowther, P., \& Orefice, C. (2015). Co-creative events: Analysis and illustrations. In G. Richards, L. Marques, \& K. Mein (Eds.), Event design: Social perspectives and practices (pp. 122-136). London: Routledge.

de Moragas, M., \& Botella, M. (2002). Barcelona: L'herència dels jocs. Barcelona, Spain: Centre d'Estudis Olimpics UAB.

Dodd, D. (1999). Barcelona, the making of a cultural city. In D. Dodd \& A. van Hemel (Eds.), Planning cultural tourism in Europe: A presentation of theories and cases (pp. 53-64). Amsterdam: Boekman Stichting.

Duran, P. (2002). The impact of the Olympic Games on Tourism Barcelona: The legacy of the Games 1992-2002. Barcelona, Spain: Centre d'Estudis Olimpics UAB.

Durkheim, E. (1915). The elementary forms of the religious life. London: George Allen \& Unwin.

Esports Barcelona. (2013). L'esport a Barcelona: Valoració 2013 dels impactes socials, laborals I econòmics. Retrieved May 20, 2015, from http://esports.bcn.cat/ sites/default/files/Informe_EsportBCN_febrer15_v7.pdf

Farías, I. (2012). Destinations as virtual objects of tourist consumption. In R. van der Duim, C. Ren, \& G. T. Jóhannesson (Eds.), Actor-network theory and tourism: Ordering, materiality and multiplicity (pp. 128-145). Abingdon: Routledge.

Getz, D. (2005). Event management \& event tourism (2nd ed.). Binghamton, NY: Cognizant Communication.

Getz, D. (2012). Event studies: Theory, research and policy for planned events. London: Routledge.

Getz, D., \& Page, S. J. (2015). Progress and prospects for event tourism. Tourism Management, 52, 593-631.

Granovetter, M. S. (1973). The strength of weak ties. American Journal of Sociology, 78, 1360-1380.

Hall, C. M. (2012). Sustainable mega-events: Beyond the myth of balanced approaches to mega-event sustainability. Event Management, 16(2), 119-131.

Hargreaves, J. (2000). Freedom for Catalonia? Catalan nationalism, Spanish identity and the Barcelona Olympic Games. Cambridge, UK: Cambridge University Press.

Hjalager, A.-M. (2009). Cultural tourism innovation systems-The Roskilde Festival. Scandinavian Journal of Hospitality and Tourism, 9(2-3), 266-287.
Hughes, G. (1999). Urban revitalization: The use of festive time strategies. Leisure Studies, 18(2), 119-135.

Jarman, D. (2013). Social network analysis and cultural festival communities. Paper presented at "Making Waves ICE2013,” July, Bournemouth University, Poole, UK.

Jarman, D., Theodoraki, E., Hall, H., \& Ali-Knight, J. (2014). Social network analysis and festival cities: An exploration of concepts, literature and methods. International Journal of Event and Festival Management, 5(3), 311-322.

Kammeier, H. D. (2002). Coping with "pulsar effects": Towards a conceptual framework. Paper presented at the 38th ISOCARP Congress, September, Athens, Greece.

Kavaratzis, M., \& Ashworth, G. (2015). Hijacking culture: The disconnection between place culture and place brands. Town Planning Review, 86(2), 155-176.

Latour, B. (2005). Reassembling the social. An introduction to actor-network-theory. Oxford: Oxford University.

Luhmann, N. (1995). Social systems. Stanford, CA: Stanford University Press.

Magaudda, P., \& Colombo, A. (2010). The Sónar festival. In L. Giorgi, (Ed.), European Arts Festivals. Cultural Pragmatics and Discursive Identity Frames. EU Seventh Framework Programme.

Mackellar, J. (2006). Conventions, festivals, and tourismthe network that binds. Journal of Convention \& Event Tourism, 8(2), 45-56.

Moran, C. (2013). Time as a social practice. Time and Society. DOI: 10.1177/0961463X13478051

Meyerscough, J. (2011). Glasgow cultural statistics digest. Glasgow, Scotland: Glasgow City Council. Retrieved May 20, 2015, from http://www.understandingglasgow. com/assets/0000/5013/Cultural_Statistics_1_Feb_ pdf_2_.pdf

Pablo, J. (1998). Arxiu festiu. Gràcia. Festa Major 18171943. Barcelona, Spain: Universitat Autònoma de Barcelona.

Pascual, J., Balta, J., \& Delgado, E. (2001). Volunteering and culture in Catalonia. Karis, 11, 63-77.

Putnam, R. D. (2000). Bowling alone: The collapse and revival of American community. New York: Simon \& Schuster.

Rennen, W. (2007). CityEvents: Place selling in a media age. Amsterdam: Amsterdam University Press.

Richards, G. (2007). Culture and authenticity in a traditional event: The views of producers, residents, and visitors in Barcelona. Event Management, 11(1-2), 33-44.

Richards, G. (2010). Leisure in the network society: From pseudo-events to hyperfestivity? Tilburg, Netherlands: Tilburg University.

Richards, G. (2013). Events and the means of attention. Journal of Tourism Research \& Hospitality, 2(2), 1-5.

Richards, G. (2015). Imagineering events as interaction ritual chains. In G. Richards, L. Marques, \& K. Mein (Eds.), Event design: Social perspectives and practices (pp. 14-24). Routledge: London.

Richards, G., \& Palmer, R. (2010). Eventful cities: Cultural management and urban revitalisation. Routledge: London. 
Richards, G., \& Wilson, J. (2006). Developing creativity in tourist experiences: A solution to the serial reproduction of culture? Tourism Management, 27, 1209-1223.

Rivera, M. A., \& Croes, R. (2012). CNSJF 2012 report: Exceeding expectations. Orlando, FL: Rosen College of Hospitality Management.

Rojek, C. (2013). Event power: How global events manage and manipulate. London: Sage.

Rojek, C. (2014). Leaderless organization, world historical events and their contradictions: The "Burning Man City.” Cultural Sociology, 8(3), 351-364.

Rotterdam Festivals. (2015). Event calendar 2015; focus on identity and energy of Rotterdam. Retrieved May 20, 2015, from http://www.rotterdamfestivals.nl/business/ news/event-calendar-2015-presented/

Schüssler, E., Rüling, C.-C., \& Wittneben, B. (2013). On melting summits: The limitations of field-configuring events as catalysts of change in transnational climate policy. Academy of Management Journal, 57(1), 140-17.

Sewell, W. H. (1996). Historical events as transformations of structures: Inventing revolution at the Bastille. Theory and Society, 25, 841-881.

Silvanto, S., \& Hellman, T. (2005). Helsinki-the festival city. In L. Lankinen (Ed.), Arts and culture in Helsinki (pp. 4-9). Helsinki, Finland: City of Helsinki.

Simons, I. (2014). How to slay a dragon slowly: Applying slow principles to event design. In G. Richards, L. Marques, \& K. Mein (Eds.), Event design: Social perspectives and practices (pp. 78-91). Routledge: London.
Smith, A. (2012). Events and urban regeneration: The strategic use of events to revitalise cities. Routledge, London.

Stokes, R. (2004). A framework for the analysis of events tourism knowledge networks. Journal of Hospitality and Tourism Management, 11(2), 108-122.

Stone, C. A. (1993). Urban regimes and the capacity to govern: A political economy approach. Journal of Urban Affairs, 15, 1-28.

van Aalst, I., \& van Melik, R. (2012). City festivals and urban development: Does place matter? European Urban and Regional Studies, 19, 195-206.

van der Duim, R. (2007). Tourismscapes an actor-network perspective. Annals of Tourism Research, 34(4), 961-976.

van Ingen, E., \& Dekker, P. (2011). Dissolution of associational life? Testing the individualization and informalization hypotheses on leisure activities in the Netherlands between 1975 and 2005. Social Indicators Research, 100(2), 209-224.

Ziakas, V. (2014). Planning and leveraging event portfolios: Towards a holistic theory. Journal of Hospitality Marketing \& Management, 23(3), 327-356.

Ziakas, V., \& Boukas, N. (2014). Post-event leverage and Olympic legacy: A strategic framework for the development of sport and cultural tourism in post-Olympic Athens. Journal of Sports, 1(2), 87-101.

Ziakas, V., \& Costa, C. (2011). The use of an event portfolio in regional community and tourism development: Creating synergy between sport and cultural events. Journal of Sport \& Tourism, 16(2), 149-175. 